\title{
MÚSICA I FESTA: ALGUNES REFLEXIONS SOBRE LES PRÀCTIQUES MUSICALS I LA SEVA DIMENSIÓ FESTIVA ${ }^{1}$
}

Josep MARTí

\begin{abstract}
This article deals with the relationship between music and festive practices. After having delimited the idea of Fiesta from an anthropological point of view, the author traces the main types of different musical manifestations as they appear in festivals and celebrations. The last part of the article seeks to explain the importance of music in festive practices basically through the fact of the extreme complicity of music with the four constants, formulated by Vittorio Lanternari, regarding the idea of Fiesta: sociability, participation, rituality and the temporal and simbolic annulment of order.
\end{abstract}

\section{Resum}

En aquest article es tracta la relació entre les pràctiques musicals i la festa. Després de delimitar la idea de festa des d'una perspectiva antropològica, es delineen els principals tipus de manifestacions musicals talment com apareixen a les celebracions festives i s'intenta explicar la rellevància del fet musical en l'àmbit festiu a partir principalment de la estreta complicitat de la música amb les quatre constants que Vittorio Lanternari va formular per entendre la festa: sociabilitat, participació, ritualitat i l'anul·lació temporal i simbòlica de l'ordre.

\section{Algunes consideracions al voltant de la idea de festa}

Unes reflexions sobre les relacions que podem establir entre festa i pràctiques musicals demana que a tall d'introducció, fem algunes precisions sobre què vol dir la idea de festa, per tal d'acotar el seu camp semàntic. En el llenguatge quotidià s'empra el mot festa amb significacions diverses. En ocasions implica només una oposició a dia feiner (avui faig festa), en altres s'empra en el sentit de commemoració (la festa de l'onze de setembre, la festa dels morts) o bé fa referència a una celebració de caire lúdic (festa major). Al llarg d'aquesta exposició, però, entendré com a festa aquell acte col-lectiu que caracteritzat per les constants de sociabilitat, participació, ritualitat i l'anul·lació temporal i simbòlica de l'ordre, posseeix trets d'excepcionalitat, pressuposa el gaudi i se celebra en honor d'algú, alguna cosa o esdeveniment.

1. Aquest article ha estat desenvolupat dins del context del projecte d'investigació Festa $i$ ciutat: pluriculturalitat i integració (P.N. I+D, cofinançat amb fons FEDER).

Anuario Musical, 57 (2002) 
En aquesta definició he tingut en compte aquelles constants que l'antropòleg italià Vittorio Lanternari considerà definitòries per a la idea de festa²:

1. La sociabilitat

2. La participació

3. La ritualitat

4. L'anul·lació temporal i simbòlica de l'ordre.

La festa constitueix un fenomen social per definició, donat que, tal i com ja ha estat apuntat per molts investigadors, una festa no pot ser mai cosa de només una única persona. Festa $\mathrm{i}$ comunitat, sigui aquesta petita o gran, apareixen sempre indissolublement lligades. Festa és diversió, però la clau de tota festa rau en la seva capacitat de fer vibrar a l'uníson tothom que hi participa. D'aquí que quan s'aconsegueix, la festa és un poderós element de sociabilitat. S'ha dit de les festes que no són només portes sinó també ponts que uneixen diferents classes socials, grups d'edat, de gènere o cultures ${ }^{3}$. Però d'altra banda, també sabem que no tots aquests diferents estrats poblacionals s'aprofiten de la festa de la mateixa manera, i que per molt que s'idealitzi la capacitat unificadora de la festa, tampoc hem d'esperar que les fronteres internes que una societat determinada pot erigir en base als criteris de gènere, edat, classe o provinença ètnica no s'hagin de manifestar també en els comportaments festius d'aquesta societat. Però malgrat aquestes limitacions, allò que també és cert, és que les festes ofereixen variades possibilitats d'interacció social que no es presenten a la vida quotidiana.

Festa vol dir participació. Evidentment, aquesta participació pot ser, però, de natura força diferent. Detlev Sivers, en un article que va publicar sobre la festa com a sistema de comunicació, ens parlava de participació activa i participació passiva. La participació activa es refereix a tots aquells agents socials que intervenen en la concepció i organització de la festa, així com els que tenen un paper actiu en el desenvolupament dels diferents actes. La participació passiva fa al·lusió a aquelles persones que es limiten al paper d'observadors ja sigui estant presents en el mateix lloc de la festa, o bé seguint-la a través dels mitjans de comunicació, un aspecte aquest darrer cada cop més acusat ${ }^{4}$. Sens dubte, això que hem anomenat participació activa constitueix el nucli més important de la festa. Sense això no hi hauria festa pròpiament dita ja que si aquesta es limités a la participació passiva, aleshores seria més indicat parlar senzillament d'espectacle. Però això no ens ha de fer infravalorar l'àmbit de la participació passiva que també pot tenir no poca importància per al desenvolupament d'algunes festes ${ }^{5}$. La presència d'aquests espectadors de manera directa o a través dels mitjans de comunicació, pot influir fortament en la dinàmica de la festa i en la percepció social que es té d'ella. D'aquí que també s'hagin de tenir en

2. Cfr. Vittorio Lanternari, "Spreco, ostentazione, competizione economica. Antropologia del comportamento festivo", en: C. Bianco i M. Del Ninno, Festa. Antropologia e semiotica, Firenze: Nuova Guaraldi Editrice, 1981 , p. 136.

3. Cfr. Enrique Gil Calvo, Estado de Fiesta, Madrid: Espasa-Calpe, 1991, p. 41.

4. Kai Detlev Sievers, Das Fest als kommunikatives System, «Kieler Blätter zur Volkskunde» 18, 1986, p. 12.

5. Vegeu, per exemple, Josep Martí, "Turismo y Tradición en la Semana Santa del Bajo Aragón”, en: Pedro Rújula (ed.), Entre tambores. El Bajo Aragón durante la Semana Santa, Zaragoza: Edelvives, 2002, pp. 105-120. 
compte a l'hora de reflexionar sobre els agents socials de la festa. Aquesta important constant de la festa, la participació, fa que haguem d'entendre la festa com un camp molt rellevant per a la interacció social.

La dimensió cerimonial apareix íntimament lligada a la noció de festa, i això implica un important contingut en elements rituals, en el sentit més ampli del terme: és a dir, accions summament codificades amb una finalitat no instrumental sinó expressiva. Tota festa té els seus rituals, religiosos o profans. Estem parlant, doncs, d'elements morfològics amb una sintaxi molt concreta que, evidentment, estan condicionats històricament i culturalment.

Precisament aquest component ritual juga un paper molt important en la festa com a element de comunicació, comunicació entesa no només com intercanvi d'informació entre les persones sinó com un procés d'enteniment intersubjectiu emmarcat en regles sancionades socialment i amb un intercanvi de continguts emocionals ${ }^{6}$. Els components rituals són a més de portadors de determinades informacions, elements de regulació d'interacció i comportament social. No és només important allò que es diu, sinó, també, com es diu.

La darrera constant formulada sobre la festa per Vittorio Lanternari, l'anul·lació temporal i simbòlica de l'ordre, constitueix també un important tret de la dimensió festiva. El model del Carnestoltes ens apareix com a paradigmàtic per a aquesta característica, però evidentment, amb major o menor intensitat, aquesta constant es troba també en qualsevol tipus de festa: l'ús de disfresses, el consum desmesurat d'aliments o begudes alcohòliques, el tornar tard a casa, etc. Aquesta anul·lació temporal i simbòlica de l'ordre permet o facilita, també, l'aparició d'un altre element al qual algun teòric l'hi ha donat una importància destacada a l'hora de definir l'essència de la festa: l'espontaneïtat. De fet, l'espontaneïtat juga un paper important en la festa. Hi ha, com per exemple D. Grisoni, qui ha afirmat que la vertadera festa és només aquella que és total-

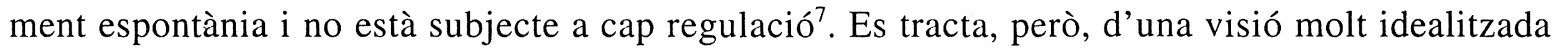
del fenomen festiu, que en qualsevol cas només pot ser veritat per a un àmbit molt reduït i limitat de les festes. Es pot dir que l'espontaneïtat és inherent a la dimensió festiva, però parlar de festa implica, de fet, parlar també d'institucionalització, i en aquest cas difícilment podem parlar de festa sense que hi hagi un mínim d'organització, més si tenim en compte la importància de la dimensió ritual.

La festa es troba, en definitiva, emmarcada en la tensió dialèctica entre dos pols oposats: espontaneïtat versus planificació, caos versus ordre. L'espontaneïtat la trobem en l'origen de moltes festes. Al llarg, però, de la continuïtat cíclica de la festa a través del temps, els seus continguts es van formalitzant de manera creixent i gradual. El caràcter espontani que tenien en un principi les festes per celebrar la victòria del Club de Futbol Barcelona, en les quals els seguidors es congregaven a la font de Canaletes a la Rambla, ha donat pas a través dels diversos anys ja de tradició d'aquesta pràctica a comportaments més formalitzats i ritualitzats.

6. Cfr. K. D. Sievers, op. cit., p. 5.

7. Cfr. Jean Maisonneuve, Les rituels, Paris: Presses Universitaires de France, 1988, p. 51; al respecte vegeu també Hermann Bausinger, “'Ein Abwerfen der grossen Last...' Gedanken zur städtischen Festkultur”, en: Paul Hugger (ed.), Stadt und Fest. Zu Geschichte und Gegenwart europäischer Festkultur, Stuttgart: W\&H Verlags AG, 1987, pp. 255-256. 
A més però de les quatre constants de la festa formulades per Lanternari, ningú no pot posar en dubte que el gaudi és un element imprescindible de la festa. La festa s'associa a una commemoració, però també hi ha commemoracions que defugen la dimensió festiva. La celebració d'un Onze de Setembre, per exemple, no és una festa en el sentit antropològic del terme que emprem en aquest article. Per als catalans que no romanen indiferents a l'Onze de Setembre, la diada té un caràcter commemoratiu o bé fins i tot reivindicatiu. Però a aquesta festa del calendari li manca el sentit inherent del gaudi. Res no diu, però, que una determinada celebració que en un principi no s'entendria com una festa, en el sentit que donem aquí a aquest concepte, pugui acabant essent-ho. És el cas d'un Catorze de Juliol a França; o és també el cas específic de la Setmana Santa talment com en l'actualitat s'entén per exemple a Calanda, al Baix Aragó. Aquesta celebració ha esdevingut actualment una festa, i de tanta importància per cert, que per a la pròpia població posseeix més rellevància que la tradicional festa major d'aquesta localitat que se celebra en honor de la Mare de Déu del Pilar ${ }^{8}$.

El gaudi, doncs, és conditio sine qua non per a la festa. Però d'altra banda, tal com ja ha estat apuntat encertadament per altres investigadors, la natura de la festa no exclou pas el treball o l'esforç ${ }^{9}$. Una festa cal preparar-la, cal atendre-la en el moment en el qual es realitza i cal eliminar tot allò que els seus excessos han produït per tal de poder tornar a la normalitat un cop la festa ha conclòs. Però al capdavall, tots aquests treballs afegits també es fan en comunitat, i per tant, també impliquen sociabilitat i participació. Clar que aquesta relació entre treball i gaudi no es dóna de la mateixa manera a totes les festes. Aquesta relació, la variabilitat de la qual ens ajuda a fer distincions importants entre els diferents tipus de festa, ens duu a la conveniència de distingir entre els rols d'organitzador i convidat. La sociabilitat i participació com a constants de la festa assoleixen la seva màxima expressió quan els rols d'organitzador i convidat es fonen, mentre que quan hi ha una clara línia demarcadora entre els dos rols, l'activitat tendeix a l'espectacle. Pel que es refereix al primer cas, és el que trobem, per exemple, en la festa de la revetlla de Sant Joan que celebra un grups d'amics. Tots els membres de la colla contribueixen al treball de la festa. Fan els preparatius, s'ho passen bé en comunitat i s'ocupen també de realitzar les corresponents tasques de neteja un cop la festa s'ha acabat. Molt diferents són les festes organitzades per les institucions, tal com ho pot ser la festa de la Mercè a la ciutat de Barcelona, tot $\mathrm{i}$ que en aquest darrer cas el moviment associatiu tingui també la seva importància. A la festa de la Mare de Déu de la Mercè de Barcelona, hi ha una clara línia entre organitzadors -en molt bona part tècnics de l'ajuntament-i convidats. Tot això fa que la vivència de la festa sigui bastant diferent segons el model del qual es tracti. Aquesta diferència l'hem percebut tots quan ens reunim amb un grup d'amics per menjar. Hi ha la possibilitat d'asseure's a la taula ja ben parada després que l'amfitrió hagi dut a terme els preparatius. Però també hi ha la variant en la qual tot el grup d'amics col-labora en la preparació de l'àpat. En aquest cas, el treball que es realitza a la cuina o a la barbacoa quan es fa a l'aire lliure, tal com tots haurem tingut ocasió d'experimentar, es

8. Cfr. Josep Martí, El Folklorismo: Uso y abuso de la Tradición, Editorial Ronsel, Barcelona 1996, pp. 129-136. 9. Cfr. Enrique Gil Calvo, op. cit., p. 21. 
presta de manera especial a la sociabilitat. És possible que algunes d'aquestes persones no es coneguessin abans d'aquesta trobada. Però a l'asseure's a la taula, i després d'haver passat pels treballs conjunts de preparació del menjar ja no tenen la sensació d'ésser mers desconeguts. El treball previ a l'àpat els ha socialitzat.

I si el gaudi és també important per entendre què és una festa, tampoc no hem d'oblidar que tota festa ha de tenir un motiu de celebració que vagi més enllà del mer entreteniment. Talment com deia en línies anteriors, una festa se celebra en honor d'algú, alguna cosa o esdeveniment. Això ens permet distingir entre festa com a institució, d'altres tipus d'activitats que també poden incloure elements característics de la dimensió festiva. Així, per exemple, les fires comercials, els festivals de música, o les reunions al carrer de joves en algunes ciutats espanyoles que hom anomena botellón també poden posseir molt fàcilment connotacions festives. Però tots sabem, també, que totes aquestes activitats no són festes. Difícilment cap dels participants a aquestes activitats diran me'n vaig a la festa per dir que pensa visitar la fira, o participar en el concert o a la reunió d'amics del botellón. Tenen finalitats molt concretes. Les fires allò que pretenen en primer lloc és vendre; el festival de música oferir la possibilitat d'escoltar música; el botellón oferir un marc d'interacció per satisfer la necessitat de sociabilitat dels joves. En tots aquests casos, la dimensió festiva apareix com un mer complement destinat a facilitar l'assoliment d'una finalitat molt determinada. El cas de la festa, en la significació més pròpia de la paraula, és diferent. El sentit principal de la festa és precisament la realització o producció expressa de la dimensió festiva. En una festa al carrer també hi poden haver parades on es venguin els productes més variats, també hi sol haver música en directe i també es pot desenvolupar sociabilitat al voltant de l'ampolla de cervesa. Però això són aspectes parcials de la festa. El sentit principal de la festa és principalment el de passar-s'ho bé, a partir de la idea de celebració, i mitjançant les constants esmentades per Vittorio Lanternari: sociabilitat, participació, ritualitat i anul·lació temporal i simbòlica de l'ordre.

\section{Les manifestacions musicals en la festa}

Realment no es concep una festa sense música. Per poc que pensem, no costa gaire de trobar unes primeres raons a aquesta constatació, especialment si tenim en compte que entre les principals funcions que podem assignar a la música es troben la lúdica i la de vehicular continguts de significació, a més del fet de què les pràctiques musicals constitueixen un acte social per excel·lència.

És tanta la imbricació de música i festa, que, en ocasions, el nom aplicat a gèneres musicals constitueix un equivalent de festa, talment com succeeix amb el fandango. Al segle XVIII tant a Espanya com a Amèrica ja s'usava fandango per senyalar una festa on es canta i es balla ${ }^{10}$.

10. Cfr. Miguel Ángel Berlanga Fernández, Los fandangos del Sur. Conceptualización, Estructuras Sonoras, Contextos Culturales, Tesi doctoral presentada a la Universitat de Granada, 1998, pp. 69-71. 
I actualment, en les organitzacions institucionals d'actes festius, la importància que rep la música no només com a element de contingut sinó fins i tot com a element articulador de la festa, fa que amb tot encert s'hagi arribat a dir que: “Antaño la música servía para festejar; cada vez más es ella la que organiza los festejos" ". En aquest sentit, podem entendre ben bé la música com a vertadera "transposició sonora de la festa"

Una ullada a les diferents manifestacions festives que es produeixen en el si de la nostra societat ens permet delimitar cinc grans àmbits diferenciats en els quals la música contribueix a subratllar o àdhuc a donar forma a l'esperit festiu: el ball, les manifestacions cerimonials o rituals, l'espectacle, els repertoris cançonístics específics i la música ambiental o paisatge sonor.

1. El ball. Es tracta de la manifestació de tipus musical que primer ens ve al cap quan pensem en la relació entre música i festa. Òbviament, no tota festa inclou forçosament el ball però aquest constitueix sens dubte un tret característic de la festa. Dins d'aquest àmbit em refereixo exclusivament als balls de tipus participatiu talment com apareixen, per exemple, a les nostres festes majors en forma de ball d'envelat o de sardanes, en el ball propi de les revetlles o el que sovint es realitza en unes noces. Es tracta de balls que quan s'organitzen dins d'un àmbit social reduït (festa major d'un petit municipi, grup d'amics, festa familiar, etc.) intenten acomplir uns criteris d'adequació generalitzats, és a dir, que acompleixin les expectatives de la major part dels participants a la festa. En el cas de les festes de grans dimensions, com la festa major d'una ciutat, és molt més fàcil, però, que els balls que s'ofereixen es guiïn també per criteris d'adequació específics, segons gustos molt més concrets (música makina, salsa, balls tradicionals...) o fins i tot per criteris d'edat, talment com podem observar en molts programes de festes majors en els quals s'anuncien explícitament balls per a la 3 ra edat, per a joves o infantils.

2. Manifestacions cerimonials o rituals. En aquest àmbit trobem totes aquelles pràctiques musicals relacionades amb elements rituals de les festes i desenvolupades dins d'un context cerimonial que pot ser tant de tipus religiós com profà. Hi trobem, per tant, des de tot aquell repertori musical emprat en rituals litúrgics i paralitúrgics (la missa baturra dels aragonesos en el dia del Pilar, el cant dels goigs, el Cant de la Sibil-la...) fins a les músiques que acompanyen desfilades del caire més divers (els alardes del País Basc, els correfocs, els cercaviles...) o la gran varietat de danses cerimonials pròpies de les nostres festes (ball de l'àliga, balls de bastons...).

Dins de les funcions simbòliques del fet musical, aquest tipus de manifestacions actuen sovint de marcadors. Acompleixen funcions de marcadors espacials (el cercavila), temporals (les dianes de festa), identitaris o representatius per a una determinada localitat o col-lectiu (moltes de les danses cerimonials, els goigs, etc.) o bé marquen també moments forts de la festa (danses executades tot just al finalitzar la missa major, el ball de nit que clou la festa, el Happy birthday

11. Francisco Cruces, Fiestas de la Ciudad de Madrid. Un estudio antropológico, Tesi doctoral presentada a la UNED, Madrid 1995, p. 371.

12. Bernard Lortat-Jacob, Musiques en fête, Nanterre: Société d'ethnologie, 1994, p. 14. 
to you que es canta en el moment de treure el pastís amb les espelmes en ocasió d'una festa d'aniversari).

Si una de les característiques dominants del ball que esmentàvem en el primer apartat és la modernitat, és a dir el fet de voler-se adequar a unes modes o sensibilitat actuals, en el cas de les manifestacions cerimonials o rituals allò que predomina és el conservadorisme, consequiència lògica de les funcions simbòliques que acompleixen. Aquest conservadorisme s'aprecia tant en el nivell formal de les manifestacions musicals i coreogràfiques en concret, com en la dimensió de l'ús, donat que es conserven unes pràctiques clarament desfasades quant a les seves funcions primigènies. Aquests tipus de manifestacions solen suggerir també lligams emocionals molt forts entre el conjunt d'actors socials que hi participen.

3. Espectacles. En aquest àmbit caldria englobar tot aquell tipus de manifestacions musicals que estan concebudes en primer lloc com a espectacle, i, per tant, amb una clara línia divisòria entre executants i públic. L'oferta d'activitats dins el marc festiu en forma de concert, recital, espectacle de dansa o concursos constitueix un element força característic de les festes actuals. La tipologia de les músiques que poden ser susceptibles de ser programades en les festes és d'allò més variat: bandes de música, corals, cantautors, rock, folk, clàssica...

En aquest cas, doncs, trobem com a element característic -a diferència de l'àmbit del ball esmentat anteriorment- la participació passiva: parlem d'espectadors. Des del punt de vista dels actors socials, la diferència entre les actuacions musicals i coreogràfiques enteses com a espectacle o com a manifestacions cerimonials o rituals està també ben clara. En ambdós casos podem trobar una nítida demarcació entre participants actius i passius. Però les diferències les trobem bàsicament en la contextualització, i en les interpel-lacions simbòliques i a l'emocionalitat que aquestes manifestacions suggereixen en els agents socials. No cal dir, també, que la realització d'un mateix producte musical o coreogràfic pot ser entesa com a espectacle o bé com a manifestació de caire cerimonial segons el context. La realització, per exemple, del ball de les almorratxes a Lloret el dia de Santa Cristina cal entendre-la com de tipus cerimonial. Quan aquesta mateixa dansa es realitza dalt de l'escenari en el context d'un espectacle de danses tradicionals en les festes de qualsevol altra ciutat catalana, caldria parlar aleshores d'espectacle ${ }^{13}$.

4. Repertoris cançonístics específics. Dins de les diferents manifestacions musicals que podem trobar a les festes resulta també apropiat distingir els repertoris cançonístics específics. Són moltes les festes que es caracteritzen per posseir un repertori cançonístic propi. Aquest tipus de manifestació musical constitueix com és evident un àmbit diferenciat dels esmentats anteriorment. Els exemples més paradigmàtics són els de Nadal i Carnestoltes. Però els casos d'esdeveniments festius que comporten un repertori cançonístic específic són evidentment nombrosos; pensem, per exemple, en les cançons de sa ximbomba a les festes de Sant Antoni de Sa Pobla a Mallorca. En

13. Això no evita que dins de la dinàmica folklorística resulti també interessant de constatar una certa espectacularització de les manifestacions cerimonials i rituals realitzades en el seu context tradicional. Vegeu, per exemple, al respecte Josep Martí, op. cit. (2002).

Anuario Musical, 57 (2002) 
tots aquests casos, les cançons poden ser entonades pels mateixos participants a la festa tant fora de contextos cerimonials específics com també fora de les coordenades pròpies de l'espectacle.

5. Música ambiental o paisatge sonor. I, per últim, crec que també aquesta categoria mereix ésser tinguda en compte de manera diferenciada dins de les diferents manifestacions musicals que es produeixen en el context d'una festa. Es tracta senzillament d'aquelles músiques que no serveixen per ballar, ni posseeixen funcions rituals, ni estan pensades per a l'escolta contemplativa com en el cas del concert o recital. Simplement són músiques que posseeixen les mateixes característiques i funcions de l'anomenada música ambiental: una música pensada per a ser sentida però no per a ser escoltada i que és percebuda de forma intermitent pels agents socials $^{14}$. Es tracta senzillament de la música que es fa sentir pels altaveus o que també és executada per músics com és el cas concret, per exemple, del carnaval de Laza a Galícia en el qual un grup de gaiteiros amenitza diferents moments de la festa que, en principi, no tenen cap necessitat de l'acompanyament musical ${ }^{15}$.

En aquest cinquè àmbit podríem incloure també tot aquell tipus de manifestacions sonores que van més enllà de l'esfera estrictament musical i que formen part del soundscape o paisatge sonor en el sentit de Murray R. Schafer ${ }^{16}$. Sens dubte, l'esclat continu de petards a les nostres festes de Sant Joan o les mascletades del País Valencià, pertanyen a aquesta categoria. Una anàlisi sobre música i festa quedaria incomplet si no prestéssim també una certa atenció al fenomen del paisatge sonor, tot i que no es tracti sempre de música pròpiament dita. Sovint, la personalitat sonora d'una festa no es configura només amb els concerts, recitals i balls sinó també a través dels seus sorolls, sorolls que per la intencionalitat amb la qual es produeixen i la seva contextualització adquireixen dimensions vertaderament festives.

\section{Les aportacions de la música a les constants de la festa}

Aquests cinc diferents àmbits de manifestacions musicals ens donen una idea de la importància que té la música en la festa. Ara ens hauríem però de preguntar-nos el perquè d'aquesta importància. I la resposta la trobem precisament en l'adequació del fenomen musical a les constants de la festa formulades per Lanternari i que ja hem esmentat en línies prèvies: sociabilitat, participació, ritualitat i l'anul·lació temporal i simbòlica de l'ordre; a aquestes constants caldria afegir el cinquè element que també resulta imprescindible per entendre la festa: la idea de gaudi. No cal dir que el fenomen musical mostra un extrem grau de complicitat amb aquestes diferents constants.

14. Al respecte vegeu Josep Martí, Músicas invisibles: la música ambiental como objeto de reflexión, «Antropología», 15-16, 1999.

15. Estic pensant en el cas concret de la farrapada, un dels diferents actes del carnestoltes de Laza, en el qual els participants es lliuren a una batalla campal tot tirant-se mútuament draps bruts de fang, mentre que els gaiteiros dalt d'un cadafal fan sonar els seus instruments.

16. Cfr. Murray R. Schafer, The tuning of the world, New York: Knopf, 1977. 


\section{Sociabilitat i participació}

Abans dèiem que la festa constitueix un context complex en el qual es produeix una intensa interacció social. Tota festa implica la presència de diversos agents socials, i tal com ja s'ha indicat, en una festa, condició necessària perquè tu et diverteixis és que els altres també s'ho passin bé: La clau d'una festa és el seu poder de contagi, talment com el riure o el plorar ${ }^{17}$. La festa constitueix un poderós element dinamitzador de sociabilitat i això s'aconsegueix mitjançant la participació. Aquests dos conceptes centrals: sociabilitat i participació, són també dos elements molt característics de les pràctiques musicals.

La música és un fenomen social per excel-lència, i com a tal, un fenomen productor de sociabilitat. La sociabilitat pot ésser concebuda talment com ho feia el sociòleg Georg Simmel com a sentiment social ${ }^{18}$, com la facultat o inclinació de formar comunitat ${ }^{19}$. Sociabilitat implica intersubjectivitat, allò que s'ha definit com una innata propensió humana vers el compromís i la comprensió recíproca ${ }^{20}$, una propensió que és ensems cognitiva o intel·lectual i emocional. La sociabilitat és tan important que talment com s'afirma des de la perspectiva teòrica mutualista ${ }^{21}$ "las personas están tan profundamente comprometidas recíprocamente que sólo podemos entenderlas de forma adecuada si interpretamos incluso sus nociones y actitudes aparentemente íntimas como algo interpersonal",22.

La sociabilitat es basteix mitjançant la participació. Una cosa implica l'altra. Participació és compartir una mateixa realitat, en el nostre cas, la realitat d'una execució musical viscuda per un conjunt de persones. Tant se val que es tracti d'una participació activa (el fet de cantar en grup), com passiva (el cas del públic en una actuació musical).

Amb raó s'ha afirmat que la música és una de les diferents arts amb més poder de convocatòria. No cal dir que el fet de què una persona canti per a ella mateixa mentre feineja o que un jove viatgi amb metro escoltant música amb el seu walkman són també fets musicals. Però això constitueix només un reduït apartat de l'extensa diversitat de pràctiques musicals. Fer música significa en una gran majoria de casos acomplir un acte social: la gent es reuneix per fer i fruir la música. Els concerts, recitals i balls propis de les festes constitueixen moments obligats de sociabilitat. I no és només que aquestes activitats impliquin sociabilitat per elles mateixes; són també excusa de sociabilitat. D'aquí, part del sentit que tenen les pauses en els concerts, o el costum tan estès d'anar a prendre una cervesa o una copa amb els amics després de l'actuació musical.

Les nostres pràctiques musicals són, doncs, no només consequiència de la sociabilitat sinó que en són també un vertader motor. El paper dinamitzador de la música en relació a crear o suggerir un vertader esperit col·lectiu ja ha estat subratllat per alguns investigadors. Així, per exem-

17. Cfr. E. Gil Calvo, op. cit., p. 36.

18. Citat a Alfons Silbermann, Estructura social de la música, Madrid: Taurus, 1962, p. 39.

19. Citat a A. Silbermann. op. cit. p. 64.

20. Michael Carrithers, ¿Por qué los humanos tenemos cultura? Madrid: Alianza, 1995, p. 85.

21. El terme procedeix dels psicòlegs Arthur Still i Jimm Good. Cfr. M. Carrithers, op. cit., p. 26.

22. M. Carrithers, op. cit., p. 26. 
ple, tot parlant en concret de la música en la festa a la ciutat peruana de Conima, Turino escrigué:

"Music and dance bring the state of being in sync -of being together- to a heightened level of explicitness. With each repetition of a piece in Conima, the possibility of 'being in sync' is extended and the social union is intensified, contributing to an affective intensity. [...] Not unlike making love, music and dance open the possibility for deeper physical and spiritual connections between community members. During special moments, culturaly specific rhythms and forms of movement are not merely semiotic expressions of community and identity; rather, they become their actual realization." 23

A les festes, són especialment importants aquelles manifestacions musicals que demanen una participació activa per part de les persones que les celebren. Això s'aprecia en el ball, en el cant en grup de repertoris cançonístics propis de la festa però també en les manifestacions musicals o coreogràfiques de caire cerimonial a causa del fort component emocional que suggereixen i la complicitat que impliquen amb el públic local. El bombo de grans dimensions que es col·loca al mig de la plaça major de Calanda, al Baix Aragó, en ocasió de la rompida del Divendres Sant no fa sinó senyalitzar aquesta necessitat de participació que té la festa i que en aquest cas es canalitza mitjançant la pràctica musical. Tothom que no disposi d'instrument propi està convidat a percudir aquest bombo per tal de sumar-se així a l'immens brogit de la celebració.

El gran poder de sociabilitat que té la música rau precisament en el fet de permetre una participació que implica que en un moment i lloc determinats s'apleguin una sèrie de persones i comparteixin un medi -la música- capaç de vehicular tant missatges ben concrets, com emocions. Això permet precisament arribar a experimentar aquella sensació d'efervescència col·lectiva, una expressió que s'escau ben bé a allò que les persones experimenten en un concert de rock, en la virtuosa execució d'una ària pucciniana o en un concert de la Filharmònica de Berlín. I no casualment, efervescència col-lectiva fou precisament l'expressió amb la qual el sociòleg francès Émile Durkheim va voler caracteritzar la festa ${ }^{24}$.

És precisament a causa de tots aquests factors que la música és constitueix en un element poderós per a la creació del sentiment de communitas. Les pràctiques musicals duen amb elles un tipus de participació que és versàtil donat que tant pot apel·lar a la racionalitat com al regne de les emocions. Es tracta, a més, d'un tipus de participació que no forçosament s'ha de presentar d'una manera aïllada sinó que es pot anar repetint en el temps. És el cas dels seguidors d'un determinat estil musical o d'un intèrpret que es van trobant en el temps, en cada ocasió que es presenta per escoltar la seva música. Es tracta, doncs, d'un tipus de participació, que també pot posseir durabilitat. És repetible. Això reforça sens dubte els lligams propis de la communitas. I és per aquesta raó, que quan es parla del controvertit terme de tribus urbanes, sigui la

23. Thomas Turino, Moving away from silence, Chicago: Chicago University Press, 1993, p. 111. Aquesta idea de Turino l'he extreta de Jordi Raventós, Manifestacions musicals a Barcelona a través de la festa: de les Entrades Reials a les cerimònies olimpiques, treball presentat a la Universitat de Barcelona, 2000, inèdit.

24. Cfr. Émile Durkheim, Las formas elementales de la vida religiosa, Madrid: Akal, 1982, p. 356. 
música amb molta freqüència una de les característiques bàsiques que donen personalitat als $\operatorname{grups}^{25}$.

\section{La ritualitat}

Els rituals i els comportaments ritualitzats constitueixen una part important de la festa, un aspecte que tant Lanternari, com la gran majoria dels estudiosos del fet festiu, han sabut detectar fàcilment. Està clar que, en aquest context, quan parlem d'element ritual no el circumscrivim exclusivament a l'esfera religiosa o credencial, sinó que l'apliquem també a manifestacions de caire profà.

El concepte de ritual constitueix una categoria important dins de l'antropologia. Durkheim va veure en el ritual la font mateixa de la societat; era precisament reunint-se amb altres en el ritual com la persona primitiva experimentava la seva pertinença a la societat i sentia així l'efervescència col-lectiva que mantenia la solidaritat comunal ${ }^{26}$. El ritual és un sistema d'operacions que consisteixen a repetir, com més escrupolosament possible actes codificats i immutables ${ }^{27}$. El ritual constitueix un tipus de comportament, estereotipat, previsible, prescrit, comunicatiu i aninstrumental. És prescrit perquè no depèn del caprici d'un individu sinó que és esperat per altres en forma i en una situació determinada. És aninstrumental perquè la seva execució no es considera posseïdora d'efecte directe o mecànic sobre el món extern. El ritual és conseqüència directa $\mathrm{i}$ ensems un factor generador de la sociabilitat.

Els rituals ens aporten una valuosa informació sobre la natura i característiques del context sociocultural en el qual es produeixen. No només pel fet de què recorrin als més variats mitjans d'expressió -allò que s'ha denominat el caràcter multimèdia dels rituals- ${ }^{28}$ sinó perquè al comportament ritual se li associen missatges de rellevància social per a la col·lectivitat. I no cal dir que les nostres pràctiques musicals estan pregonament amarades de comportaments ritualitzats.

Pel que respecta a la relació entre l'àmbit musical i ritual, pot ser convenient distingir entre: 1. elements rituals dins de l'esdeveniment musical; i 2. l'esdeveniment musical com a fet ritual en si.

Els elements rituals que podem detectar en qualsevol tipus de manifestació musical són diversos. Si ara prenem com exemple el concert d'una orquestra simfònica, podem observar fàcil-

25. Tribus urbanes és un concepte feble força apreciat en mitjans periodístics i entre les forces de l'ordre. No ens ha d'estranyar que la policia hagi mostrat un cert interés en determinar les tribus urbanes de les localitats on els toca actuar, senzillament perquè etiquetar facilita el control. En un extens article aparegut a «La Vanguardia» (Rafael Wirth, Jóvenes de $B C N$ [I], 14. 4.1991, Revista, pp. 1-4), l'articulista esmentava 21 diferents tribus urbanes pròpies de Barcelona. L'antropòleg o el sociòleg difícilment podrien compartir els seus criteris tipològics però tot $\mathrm{i}$ així, allò que resulta interessant és que en aquesta visió diletant del fenomen, a 9 d'aquests grups se'ls caracteritzava entre altres coses pels seus gustos musicals. Es tracta de les -segons l'articulista-tribus urbanes dels B. Boys, Hardcore-Skateboard, Lolailos o Chunguitos, Mods, Punks, Rockers, Sardanistes i Skinheads.

26. Cfr. Andrew S. Buckser, "Ritual", en: Thomas Barfield (ed.), Diccionario de Antropologia, Barcelona: Edicions Bellaterra, 2001, p. 546.

27. Cfr. Jean Cuisenier, Cérémonial ou rituel?, «Ethnologie Française» 28/1, 1998, p. 11 1998, p. 226.

28. Cfr. Rodrigo Díaz Cruz, Archipiélago de rituales. Teorías antropológicas del ritual, Barcelona: Anthropos, 
ment diferents elements rituals, cadascun d'ells amb la seva o seves significacions: L'afinació dels instruments dalt de l'escenari ${ }^{29}$ expressa el valor de la perfecció tècnica, de la professionalitat. El fet que els músics es posin dempeus a l'entrada del director es correspon amb la idea d'autoritat. La salutació mútua entre el director d'orquestra i el públic que aplaudeix marca l'inici d'una situació de sociabilitat ${ }^{30}$. La reverència que fa el director d'orquestra a la sala un cop finalitzada l'actuació es pot interpretar fàcilment com un record d'antigues relacions jeràrquiques entre els servidors -els músics- i l'autoritat que permetia i propiciava l'execució musical. Els aplaudiments del públic després de cada peça musical o el ram de flors que es lliura al director com a reconeixement del treball realitzat al·ludeix a la idea de la reciprocitat. A més a més d'aquestes accions, també posseeixen valor ritual el control corporal i silenci del públic durant tot el concert, així com el control de moviments dels músics en aquells moments en els quals les particel-les els marquen llargs compassos d'espera. Això ens fa pensar en el valor donat a la disciplina, i perquè no, també en l'aura de sacralitat i solemnitat que envolta aquesta mena de pràctiques musicals.

Si ara comparem aquests tipus de comportaments rituals amb els que es produeixen en un altre tipus de concert, hi apreciarem notables diferències, precisament perquè els missatges que vehiculen uns i altres no són els mateixos. En un concert de rock o de jazz, per exemple, hi haurà comportaments rituals que marquen els inicis i finals de les situacions comunicatives, així com comportaments que facin referència a la per a nosaltres tan important idea de reciprocitat. Hi mancaran però aquells que expressen més clarament la idea d'autoritat o disciplina. Difícilment es recorrerà a la reverència per a la salutació, i no es considera important, ans tot el contrari, que el públic s'aferri als seus seients amb un control absolut del cos. El comportament dels músics dalt de l'escenari es troba a les antípodes del que esmentàvem en el cas de l'orquestra simfònica. En un local de jazz, el pianista del grup es pot aixecar en el moment en què no ha de tocar per anar-se a buscar una cervesa; i tots coneixem altres exemples ben eloqüents quant a comportaments rituals disruptius: el del cas del músic de rock que acaba fent estralls la seva guitarra en finalitzar l'actuació o el que en el caldejament de l'actuació no té cap mania en treure's la camisa i quedar amb el tors nu. No cal dir també que els missatges aportats per tots aquests elements rituals s'associen amb altres elements propis del sistema metacomunicatiu com el dels espais i la indumentària dels músics. No és el mateix oferir un concert a sales d'audicions com el Liceu o

29. Aquesta acció té una finalitat ben concreta de caire tècnic i per tant, a primera vista, sembla que no hauria de comptar com a element ritual. Nogensmenys al llarg del temps, l'afinació dels instruments dalt de l'escenari ha acabat per assumir de manera afegida també un caire clarament ritual. Així, per exemple, en les composicions Hétérophonie (1959/61) i Dérives (1974) de Mauricio Kagel i Gérard Grisey respetivament, s'incorpora l'acció de l'afinació dels instruments com a element estètic i ritual, i deslligat, per tant, de la seva finalitat original. Cfr. Le Moigne-Mussat, Marie-Claire, "Nouveaux rituels dans la musique d'aujourd'hui", en: Marc Honegger i Paul Prevost (eds.), La musique et le rite sacré et profane, Strasbourg 1986, vol. I, p. 255.

30. En ocasions molt puntuals hom intenta contravenir de manera ben conscient aquests moments rituals. Darrerament, per exemple, en una representació de l'òpera Elektra al Teatro Real de Madrid (27 de juny de 2003), el director, Daniel Barenboim, va voler entrar a l'escenari de manera inadvertida talment com si fos un músic més per tal d'evitar els aplaudiments del públic. Això tenia la finalitat d'imposar en la representació una serenitat tràgica des del mateix començament de l'obra. El públic, però, així que va endevinar la presència del conegut director no es va poder estar d'emetre una sonora ovació. El director d'escena s'havia d'haver imaginat que no resulta tan fàcil trencar els hàbits rituals de l'audiència.

Anuario Musical, 57 (2002) 
el Palau de la Música de Barcelona on cada racó de les quals traspua solemnitat que en una fàbrica abandonada, un escenari en absolut estrany per als raves. No és el mateix que tots els músics vagin elegantment uniformats com és el cas de les orquestres simfòniques a que hom eviti expressament dur el mateix vestit talment com sempre succeeix en els grups de músiques actuals de caire popular.

Tal com han deixat ben clar els funcionalistes, una de les funcions dels rituals és la de sancionar la legitimitat de l'ordre establert. La seva estructura tendeix a reflectir i reforçar les distincions socials ${ }^{31}$. Per això, quan hi ha disconformitat amb situacions socials vigents, s'abandonen antics rituals i se'n creen de nous. El rock o el rap són disruptius, per això no comparteixen els mateixos rituals de la música clàssica, conservadora per excel·lència. Mitjançant comportaments rituals variats, les pràctiques musicals marquen i subratllen significats assignats socialment a les músiques que s'interpreten: innovació, sacralitat, etnicitat, elitisme, populisme, sentiment de communitas, transgressió, etc.

El contingut ritual a les pràctiques musicals és sempre molt important. Això no vol dir, però, que sempre en siguem conscients. Recordem allò que ens deia Christopher Small quan parlava de dos nivells diferents en els quals opera un concert simfònic: el nivell de gaudi o contemplació de les obres musicals i el nivell del ritual, que generalment passa desapercebut o ignorat a causa de què està tan proper a nosaltres ${ }^{32}$. Aquest nivell ritual forma part de l'entramat metacomunicatiu que ens diu com hem d'entendre la música que escoltem. D'aquí també que, en el context de les músiques ambientals, el fet musical vegi minvat el seu valor social. Precisament -i entre altres coses- perquè li falta el component ritual ${ }^{33}$.

Però a més de tots aquests elements rituals que trobem a les nostres pràctiques musicals, també l'esdeveniment musical en si pot representar en el seu conjunt un acte ritual. L'àmbit de la religiositat ens ofereix nombrosos exemples per a aquesta possibilitat: d'aquí que tan sovint parlem de músiques rituals. Per exemple, les pràctiques que trobem en els rituals de santería afroamericana. Però tal com dèiem abans, el concepte de ritual s'empra avui dia molt més enllà del mer fenomen religiós, i, per tant, no ens ha d'estranyar que també puguem parlar de manifestacions musicals rituals sense connotacions religioses. El tradicional concert de Cap d'Any que avui dia es retransmet a tot el món des de Viena, amb el seu repertori de valsos, polques, etc. cap bé dins d'aquesta categoria. Com també els concerts de Nadal, de fi de curs de tantes escoles i acadèmies de música, la congregació de joves a la discoteca cada cap de setmana, etc. La pràctica en contextos festius de les danses de caire cerimonial que s'executen en el marc de la tradició com per exemple els balls de bastons, de tanta difusió a Catalunya, les Moixigangues, els balls de l'àliga que trobem a diverses poblacions de Catalunya i Mallorca, etc. constitueix per ella mateixa un moment ritual, sempre almenys que es faci en el seu context original.

31. Cfr. A. S. Buckser, op. cit., p. 546.

32. Cfr. Christopher Small, "Performance as ritual: sketch for an enquiry into the true nature of a symphony concert", en: A. L. White (ed.), Lost in Music. Culture, Style and the Musical Event, London i New York: Routledge \& K. Paul, 1987 , p. 8.

33. Cfr. J. Marti, op. cit. (1999), pp. 236-238. 
Música i ritual es troben íntimament amalgamats. El fet de tenir en compte els comportaments rituals resulta imprescindible per conèixer la significació dels esdeveniments musicals. I això es posa especialment de manifest en l'àmbit festiu. En aquesta ocasió, conflueixen el caràcter ritual de l'element festiu amb la capacitat ritualitzant de la música.

\section{L'anul-lació temporal i simbòlica de l'ordre}

Al llarg d'aquestes planes hem anat veient la imbricació del fenomen musical en les constants de la participació, sociabilitat i ritualitat que Lanternari havia formulat per a la festa. Ens cal ara fer esment de la darrera d'aquestes quatre constants: l'anul·lació temporal i simbòlica de l'ordre.

L'anul-lació temporal i simbòlica de l'ordre implica la creació d'una mena de parèntesi dins del decurs de la vida quotidiana. Podem parlar, per tant, d'excepcionalitat. La contribució que en aquest respecte pot fer la música és també evident, bé que en aquest cas, i a diferència de les tres altres constants anteriorment esmentades, no sempre ens haurem de referir a propietats intrínseques de les pràctiques musicals sinó també a la seva particular articulació dins d'un context determinat.

Se m'acuden almenys quatre aspectes mitjançant els quals les nostres pràctiques musicals poden contribuir a la idea d'excepcionalitat que tan pròpia és de la festa: la rauxa, l'excés, la singularitat i la transgressió.

La idea de rauxa està íntimament associada al mateix concepte de música. Una visió transcultural ens proporcionaria prou exemples. Des del rapte maníac dels antics grecs associat a la música fins a les diferents experiències de trànsit arreu del món canalitzat mitjançant pràctiques musicals. La nostra societat actual és possiblement cada cop menys procliu a les rauxes, però les músiques que sonen als raves dels nostres joves ens donen una aproximació a aquest ús de la música. Íntimament lligada a la idea de rauxa es troba també la d'excés. Però l'excés es pot manifestar així mateix de moltes altres maneres. L'excés que trobem a les nostres festes, que conjuntament amb altres factors fan que les puguem considerar un parèntesi a la vida quotidiana, s'expressa mitjançant els àpats considerables, la beguda desmesurada i també, evidentment, en l'àmbit de les pràctiques musicals. La rica i variada oferta musical que observem en festes de les grans ciutats n'és un bon exemple. A les festes de la Mercè de Barcelona, les actuacions de grups musicals programades arriben fàcilment al centenar. Cada cop sovintegen més les festes que anuncien música i ball ininterromputs des del vespre fins a bona part de l'endemà. En l'exemple abans esmentat de la Setmana Santa de Calanda aquesta característica de l'excés apareix també ben clara: tant per la quantitat de bombos i tambors que són convocats en aquests dies festius, com per l'exageració que representa que hom no pari de tocar durant hores i hores i àdhuc al llarg de tota la nit.

La singularitat ve donada senzillament pel fet de què a les festes hom programi ofertes musicals en les quals hi intervinguin músics o grups musicals que per les seves característiques estiguin fora de les expectatives de la vida quotidiana. És el cas, per exemple, de què es porti a 
una localitat concreta un cantant o una orquestra de prestigi amb un pressupost econòmic implícit que demani un notable esforç per part del municipi. Aquesta idea de singularitat la pot donar també el fet que s'executin danses cerimonials de manera exclusiva per al dia de la festa.

I per últim, cal esmentar també el concepte de transgressió, una idea que també es pot presentar associada a la d'excés, però que també té altres tipus de manifestacions, especialment, quan ve donada pel tipus de missatges que es vehiculen a través del fet musical. Això ho trobem en moltes festes, però de manera reiterada en els tradicionals carnavals. Això fa que sovint l'autoritat s'hagi vist en la necessitat de regular mitjançant prohibicions aquestes transgressions. Un fidel testimoni d'aquest fet el constitueixen els nombrosos bàndols que els ajuntaments han editat al llarg de la història en ocasió del carnestoltes. El següent exemple és el d'un bàndol de l'ajuntament de Huelva de l'any 1902:

"Las comparsas y estudiantinas no podrán cantar más canciones que las que expresamente autorice esta alcaldía; á este fin, los directores ó encargados de aquellas quedan obligados á poner en conocimiento de mi autoridad, por escrito y bajo su firma antes del día ocho de Febrero próximo, la letra de dichas canciones." ${ }^{34}$

Les pràctiques musicals, doncs, mitjançant la rauxa, l'excés, la singularitat i la transgressió poden fàcilment implicar excepcionalitat, i amb això es constitueixen també en valuoses complicitats del fet festiu.

\section{Coda}

El tradicional concert de Cap d'Any constitueix un exemple ben il-lustratiu per a l'estreta imbricació que podem establir entre les constants de la festa formulades per Vittorio Lanternari i la música. El concert, talment com se celebra a Viena i darrerament també en altres ciutats -com per exemple a Barcelona-, constitueix ja de per si un ritual de calendari que cal incloure dins de l'ampli cicle festiu nadalenc. El fet que s'apleguin uns centenars de persones per saludar d'aquesta manera la nova entrada de l'any ja implica sociabilitat. Però en aquest concert, l'esperit festiu en el qual se l'entén fa que es modifiquin els criteris habituals d'audició de les orquestres simfòniques. Així, per exemple, en determinats moments del concert, s'anima al públic a la participació activa. El director engresca a l'auditori a taral·lejar melodies conegudes o també el convida a marcar el ritme tot picant les mans mentre l'orquestra executa la tan popular marxa de Radetzky. L'ordre seriós que caracteritza normalment els concerts simfònics es transgredeix en aquesta ocasió mitjançant petites bromes que ja gairebé han esdevingut tot un ritual: el director apareix amb una bufanda de colors virolats al coll, algun músic pot anar abillat amb una gorra d'hivern o fins i tot en la interpretació de la polca veloç de caça de J. Strauss, algú de l'orquestra pot arribar a abatre un ànec de peluix que -llençat misteriosament des d'alguna llotja- acaba als mateixos peus del director d'orquestra.

34. Citat a Francisco José García Gallardo, Música y agrupaciones de carnaval: Huelva y Cádiz, Tesi doctoral presentada a la Universitat de Huelva, 2001, p. 78. 
Entesa o no com a acte festiu en si, allò que està clar és que qualsevol pràctica musical pot molt fàcilment fer seves també les constants que Lanternari formulà per a la festa: participació, sociabilitat, ritualitat i anul-lació temporal i simbòlica de l'ordre. Si a més tenim en compte que la cinquena constant que havíem afegit a la idea de festa -el gaudi- és també un element consubstancial a la música, ens podem doncs explicar el perquè de la importància que té la música per al fenomen festiu. D'aquesta manera, podem comprendre molt millor el sentit d'entendre la música com a "transposició sonora de la festa", segons la formulació de Bernard Lortat-Jacob a la qual ja hem fet esment en planes anteriors ${ }^{35}$. I és que realment, la música és festa en potència.

\section{Bibliografia citada}

Bausinger, Hermann, “'Ein Abwerfen der grossen Last...' Gedanken zur städtischen Festkultur”, en: Paul Hugger (ed.), Stadt und Fest. Zu Geschichte und Gegenwart europäischer Festkultur, Stuttgart: W\&H Verlags AG, 1987, pp. 255-256.

Berlanga Fernández, Miguel Ángel, Los fandangos del Sur. Conceptualización, Estructuras Sonoras, Contextos Culturales, Tesi doctoral presentada a la Universitat de Granada, 1998.

Buckser, Andrew S., "Ritual”, en: Thomas Barfield (ed.), Diccionario de Antropología, Barcelona: Edicions Bellaterra, 2001, pp. 545-547.

Carrithers, Michael ¿Por qué los humanos tenemos cultura? Madrid: Alianza, 1995.

Cruces, Francisco, Fiestas de la Ciudad de Madrid. Un estudio antropológico, Tesi doctoral presentada a la UNED, Madrid, 1995.

Cuisenier, Jean, Cérémonial ou rituel?, «Ethnologie Française»28/1, 1998, pp. 10-18.

Díaz Cruz, Rodrigo, Archipiélago de rituales. Teorías antropológicas del ritual, Barcelona: Anthropos, 1998.

Durkheim, Émile, Las formas elementales de la vida religiosa, Madrid: Akal, 1982.

García Gallardo, Francisco José, Música y agrupaciones de carnaval: Huelva y Cádiz, Tesi doctoral presentada a la Universitat de Huelva, 2001.

Gil Calvo, Enrique, Estado de Fiesta, Madrid: Espasa-Calpe, 1991.

Lanternari, Vittorio, "Spreco, ostentazione, competizione economica. Antropologia del comportamento festivo", en: C. Bianco i M. Del Ninno, Festa. Antropologia e semiotica, Firenze: Nuova Guaraldi Editrice, 1981, pp. 132-150.

Le Moigne-Mussat, Marie-Claire, "Nouveaux rituels dans la musique d'aujourd'hui", en: Marc Honegger i Paul Prevost (eds.), La musique et le rite sacré et profane, Strasbourg 1986, vol. I, pp. 255-266.

Lortat-Jacob, Bernard, Musiques en fête, Nanterre: Société d'ethnologie, 1994.

Maisonneuve, Jean, Les rituels, Paris: Presses Universitaires de France, 1988.

35. B. Lortat-Jacob, op. cit., p. 14. 
Martí, Josep, El Folklorismo: Uso y abuso de la Tradición, Editorial Ronsel, Barcelona 1996

Id., Músicas invisibles: la música ambiental como objeto de reflexión, «Antropología», 15-16, 1999, pp. 227-242.

Id., “Turismo y Tradición en la Semana Santa del Bajo Aragón”, en: Pedro Rújula (ed.), Entre tambores. El Bajo Aragón durante la Semana Santa, Zaragoza: Edelvives, 2002, pp. 105120.

Raventós, Jordi, Manifestacions musicals a Barcelona a través de la festa: de les Entrades Reials a les cerimònies olímpiques, treball presentat a la Universitat de Barcelona, 2000, inèdit

Schafer, Murray R., The tuning of the world, New York: Knopf, 1977.

Sievers, Kai Detlev, Das Fest als kommunikatives System, «Kieler Blätter zur Volkskunde»18, 1986, pp. 5-28.

Silbermann, Alfons, Estructura social de la música, Madrid: Taurus, 1962.

Small, Christopher, "Performance as ritual: sketch for an enquiry into the true nature of a symphony concert", en: A. L. White (ed.), Lost in Music. Culture, Style and the Musical Event, London i New York: Routledge \& K. Paul, 1987, 6-32.

Turino, Thomas, Moving away from silence, Chicago: Chicago University Press, 1993.

Wirth, Rafael, Jóvenes de BCN [I], «La Vanguardia» 14. 4.1991, Revista, pp. 1-4. 